\title{
Experimental Models of Hemorrhagic Shock: A Review
}
A. Fülöp
Z. Turóczi
D. Garbaisz
L. Harsányi
A. Szijártó

1st Department of Surgery, Semmelweis University, Budapest, Hungary

\section{Key Words}

Animal model · Experimental model $\cdot$ Hemorrhage $\cdot$ Hemorrhagic shock · Shock

\begin{abstract}
Massive blood loss leading to hypovolemic shock is still a life-threatening situation. Recently, a great number of investigations have been conducted in order to understand the pathophysiological and immunological changes taking place during shock and to develop treatment strategies. These preclinical trials are based on animal studies. Although a wide spectrum of species and experimental models are available to researchers, it is rather difficult to create an ideal animal model to study hemorrhagic shock. A major challenge for investigators is the generation of a system which is simple, easily reproducible and standardized, while being an accurate replica of the clinical situation. The goal of this review is to summarize the current experimental models of hemorrhagic shock, highlighting their advantages and disadvantages to help researchers find the most appropriate model for their own experiments on hypovolemic shock.

Copyright $(2013$ S. Karger AG, Basel
\end{abstract}

\section{Introduction}

Shock is a functional abnormality of the circulatory system. During this condition there is a permanent difference between the capacity of blood vessels and the intravascular volume, which leads to decreased tissue perfusion, cellular hypoxia and metabolic damage (anaerobic glycolysis and lactacidemia) caused by microcirculatory disorder.

Hemorrhagic shock is one of the most common types of shock. Hemorrhage is the leading cause of morbidity and mortality in surgery and trauma patients [1]. As a result of blood loss, the ventricular diastolic filling becomes insufficient and the heart is unable to provide optimal blood flow to cells and tissues. Initially, compensatory mechanisms (neurohumoral changes such as release of catecholamines, antidiuretic hormone and atrial natriuretic peptide 
resulting in arterial vasoconstriction and increased heart rate) are able to maintain blood pressure and redistribute cardiac output in favor of vital organs such as the brain and heart $[2,3]$. However, the compensatory mechanisms are limited, and without early and effective therapy, severe cellular hypoxia and organ damage may occur, which may lead to death [4].

In recent decades, serious efforts were made to understand hypovolemic shock. A great number of preclinical trials were conducted to study pathophysiological and immunological changes during shock and to find sufficient treatment strategies. These preclinical trials are based on animal studies.

The goal of this review is to summarize the current experimental models of hemorrhagic shock, highlighting their advantages and disadvantages to help researchers find the most appropriate model for their own experiments.

\section{Animal Models}

Most of our knowledge about the pathophysiology of hemorrhagic shock comes from examination of different species. As Swanson et al. [5] wrote, 'the biomedical models are determined as surrogates for a human biologic system, that researchers use to understand physiological and pathological function of the human body and to provide a basis therapeutic intervention in diseases'.

An ideal animal model is easy to perform and suitable for drawing meaningful conclusions. A good model is a simplified, miniature counterpart of the mimicked system, which creates conditions essential for investigation. While important information can be obtained from studying model organisms, one should be extremely careful when drawing generalizations about various organizations. The different genetic background of different species can result in distinct systemic responses to the same insult. Therefore, it is by no means certain that the results can be applied to human cases.

Various types of species are used as models for the study of hemorrhagic shock. When selecting the appropriate species, several factors should be considered, for instance availability, costs (food and housing requirements), ethical issues (government laws and restrictions) and similarities to human anatomy and physiology.

Using hemorrhagic shock models for studies has two basic aims: (1) to investigate the underlying pathophysiological and pathological changes of disease and (2) to test potential preclinical approaches of therapies. Small animals are primarily used to examine the pathogenetic mechanisms of hemorrhage, while large animals are more suitable for preclinical evaluation of treatment strategies [6].

\section{Small Animal Models}

Mice are commonly used to study hemorrhagic shock. The important advantages of these animals are their cheapness, easy accessibility, short breeding time and life span, as well as the easy possibility to perform genetic modifications (knock-outs and transgenic animals). Their main disadvantages are small size and low total blood volume, which significantly complicate surgical and sampling procedures [7].

Rats are popular experimental animals as well. Because of their larger size, surgical maneuvers are technically easier to perform and more sophisticated shock models can be designed as compared to mice. Moreover, Hauser [8] reported that in rats, certain immune responses to hemorrhage may be parallel to those in humans.

However, both mice and rats are genetically distant from humans, and their cardiovascular responses to blood loss may differ as well; thus, studies carried out on small animals often require further investigations in larger animals before clinical testing. 


\section{Large Animal Models}

Dog preparations are among the oldest and best studied models in hemorrhagic shock research. Their larger size makes them ideal for investigations in the field of trauma and surgery (surgical maneuvers and sampling procedures are simpler); therefore, a number of relevant methods for creating hypovolemic shock have been described. Unfortunately, cardiovascular shock responses in dogs may not parallel those of humans. Dog spleen - as a blood reservoir - contracts during hemorrhage and increases circulating blood volume, left ventricular preload, cardiac output and hematocrit [9]. For this reason many researchers perform splenectomy before induction of hemorrhagic shock to avoid the variable degrees of autotransfusion $[10,11]$.

Pigs have also long been used in the study of hemorrhagic shock owing to their similarities to humans with regard to blood clotting mechanisms and cardiovascular and hemodynamic responses to hemorrhagic shock [12].

However, the use of pig, dog and other large animal (e.g. sheep) models has some practical disadvantages. Animal handling is financially demanding, there are very few immunologic markers available to follow the progress of the posttraumatic immune responses [13] and ethical issues are involved as well. Furthermore, these animals are also genetically distant from humans.

\section{Primate Models}

Genetically, primates are the closest animals to humans [14]. They possess similar physiologic responses to stress and hypovolemic shock, and their drug metabolism is highly homogeneous to that of humans $[15,16]$. Despite these advantages, experiments with primates are almost unaffordable for most laboratories; moreover, the use of these animals raises a number of ethical problems as well. For this reason, they are used relatively rarely.

\section{Types of Models}

In the case of hemorrhagic shock, the major challenge in setting up an adequate model is to mimic accurately the clinical situation, while maximizing reproducibility and standardization.

There are 3 basic models generally used in the study of hemorrhagic shock: (1) fixedvolume hemorrhage; (2) fixed-pressure hemorrhage, and (3) uncontrolled hemorrhage.

\section{Fixed-Volume Hemorrhage}

In these animal models, a predetermined percentage of the total calculated blood volume is removed over a time period set by the observer. Another strictly defined interval is then allowed for natural compensation. Finally, the animals are returned to their cage or are resuscitated usually with collected blood or lactated Ringer's solution [17].

The primary advantage of such models is that the physiological hemodynamic responses and the other natural compensatory mechanisms can be investigated following a specific volume of acute blood loss. On the other hand, the degree of hypotension is not properly defined; thereby, its effect cannot be adequately assessed and it is difficult to maximize experimental standardization and reproducibility. Moreover, in rats, the blood volume/body weight ratio decreases linearly with animal weight between 100 and $400 \mathrm{~g}$ (larger animals have more fat and therefore relatively less blood), significantly affecting the results. It is therefore imperative to control weight during the trial [18].

Nevertheless, this method is widely used by researchers to study shock-induced physiological and pathophysiological changes (carbohydrate metabolism, blood glucose and liver glycogen levels, anaerobic glycolysis and lactacidemia), histopathological abnormalities and 
Table 1. The most common parameters that are usually measured in different types of hemorrhagic shock models

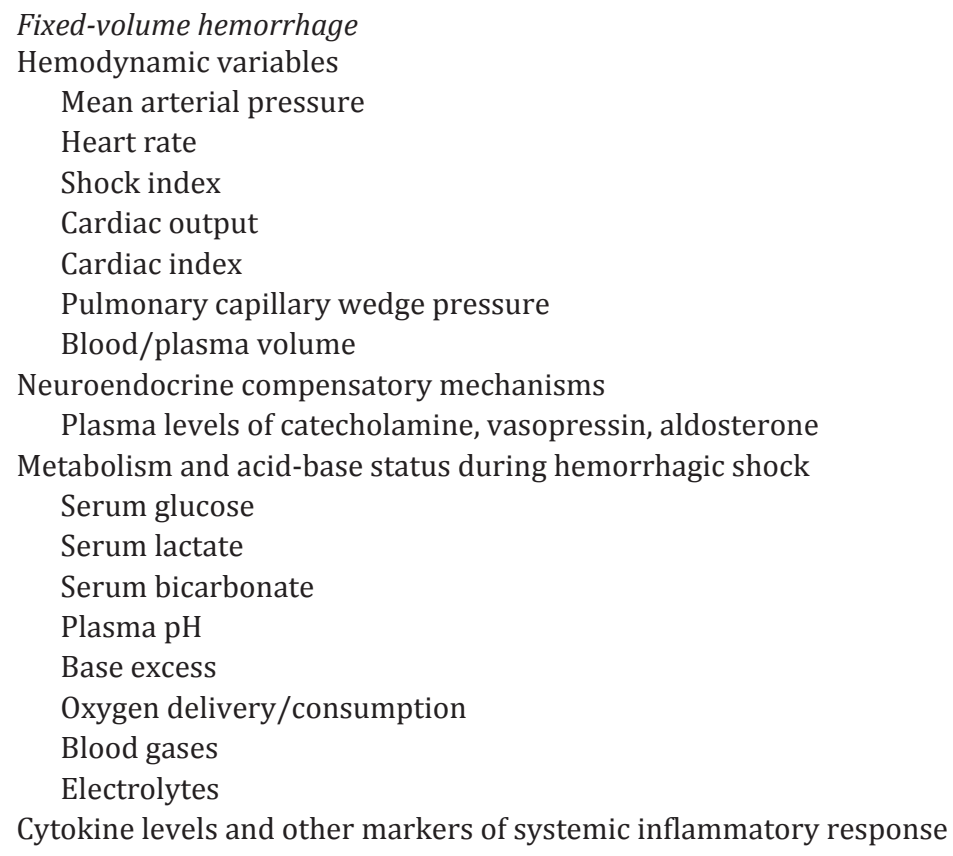

Fixed-pressure hemorrhage

Tissue microcirculation/direct imaging of tissue perfusion

Organ injury/dysfunction

Histopathology

Specific laboratory markers of organ injury

Functional tests

Hemorheologic alterations

Hemodynamic variables (see above)

Metabolism and acid-base status (see above)

Cytokine levels and other markers of systemic inflammatory response

Uncontrolled hemorrhage

Mortality/mean survival time

Amount of blood loss/evidence of rebleeding

Amount of fluid/blood required for resuscitation

Coagulation function/hemostatic potential

Hemodynamic variables (see above)

Cytokine levels and other markers of systemic inflammatory response

the efficacy of different therapeutic interventions (table 1). According to Advanced Trauma Life Support, if the bleeding rate exceeds $40 \%$ of circulating blood volume (class IV), the mortality rate is more than $30 \%$ in the clinical scenario [19]. Most investigators attempt to recreate this level of shock [12, 20-49] (table 2).

\section{Fixed-Pressure Hemorrhage}

Penfield [50] was the first to create the basics of the fixed-pressure system. In his experiment, the animals were bled until the arterial pressure reached a predetermined level, which was then maintained as best as possible by repeated hemorrhage or by fluid infusion if necessary. Later, Wiggers [51] created the classic model of fixed-pressure hemorrhage. In this experiment, animals were catheterized under anesthesia, enabling control of the volume of 
Fülöp et al.: Experimental Models of Hemorrhagic Shock: A Review

Table 2. Fixed-volume hemorrhage

\begin{tabular}{llll}
\hline Species & $\begin{array}{l}\text { Estimated blood volume } \\
\mathrm{ml} / \mathrm{kg}\end{array}$ & $\begin{array}{l}\text { Shed blood volume } \\
\text { \% of EBV }\end{array}$ & Ref. No. \\
\hline Mouse & $63-80[20]$ & $35-67$ & $21-26$ \\
Rat & $58-70[20]$ & $30-60$ & $27-34$ \\
Pig & $58-74[12]$ & $30-65$ & $35-43$ \\
Dog & $79-90[20]$ & $30-50$ & $44-49$ \\
\hline
\end{tabular}

EBV = Estimated blood volume.

blood removed and of the desired intensity of hypotensive shock. Catheters also provided access to resuscitation and drug delivery.

The primary advantage of this model is that the degree and duration of hypotension are accurately controllable by means of monitoring the blood pressure. Therefore, regarding experimental standardizations and reproducibility, the constant-pressure approaches are more reliable compared to fixed-volume models. Thus, this method can be used as a pathogenesis model to evaluate physiological changes and organ/tissue injuries at specific central pressures after hemorrhagic shock (table 1). However, isobaric models do not adequately reflect the clinical situation. The animals are under general anesthesia, and heparin is often used to suppress thrombosis and to protect the blood flow through the catheter; however, these drugs affect the results significantly (see below) [52].

Modifications of the Wiggers hemorrhagic shock preparation are widely used to this day, although there is no agreement on the blood pressure level and shock length required to set up a reliable hemorrhagic shock model. The mean arterial pressure varies between 20 and $55 \mathrm{~mm} \mathrm{Hg}$ depending on the examiner and the species. This hypotensive shock state is maintained for $15 \mathrm{~min}$, or in some studies for more than $3 \mathrm{~h}$ [53-76] (table 3).

\section{Uncontrolled Hemorrhage}

The fixed-volume and fixed-pressure models detailed above are easily reproducible and the individual test results are closely comparable. In an uncontrolled hemorrhage model, which is induced by a standardized vascular trauma (crush/laceration of liver and spleen, artery injury, amputation of appendage), the aforementioned experimental control cannot be achieved precisely; nonetheless, this model is clinically the most relevant. Considering that only the normal hemostatic mechanisms of animals can influence the progression of hemorrhage, these models seem to be the best way to preclinically test the various therapies.

According to earlier researches - performed in the 1950s and 1960s and based mostly on controlled (closed-vessel) hemorrhagic shock models - rapid fluid administration was the approved therapy for hypotension due to blood loss. In the 1990s, the use of uncontrolled (open artery) hemorrhage models led to a paradigm shift. These studies showed that aggressive fluid resuscitation before surgical control of hemorrhage increases bleeding and decreases survival due to inhibition of the formation of thrombus [17]. It should be mentioned that Cannon et al. [77] had already suggested this possibility in the early 1900s: 'Injection of a fluid that will increase blood pressure has dangers in itself. Hemorrhage in case of shock may not have occurred to a marked degree, because blood pressure has been too low and the flow too scant to overcome the obstacle offered by the clot. If the pressure raised before the surgeon is ready to check the bleeding that may take place, blood that is sorely needed may be lost.' 
Fülöp et al.: Experimental Models of Hemorrhagic Shock: A Review

Table 3. Fixed-pressure hemorrhage

\begin{tabular}{llll}
\hline Species & $\begin{array}{l}\text { Mean arterial pressure } \\
\mathrm{mm} \mathrm{Hg}\end{array}$ & $\begin{array}{l}\text { Duration of shock } \\
\text { min }\end{array}$ & Ref. No. \\
\hline Mouse & $25-40$ & $60-90$ & $53-58$ \\
Rat & $25-50$ & $15-180$ & $59-64$ \\
Pig & $25-55$ & $40-90$ & $65-70$ \\
Dog & $20-55$ & $30-180$ & $71-76$ \\
\hline
\end{tabular}

Table 4. Most common types of uncontrolled hemorrhagic shock models

\begin{tabular}{lll}
\hline Method of uncontrolled hemorrhage & Species & First author \\
\hline Vascular injury & & \\
Aortotomy & rat & Burris [78] \\
& pig & Bickell [79] \\
Iliac artery dissection & pig & Alam [80] \\
& dog & Bruscagin [81] \\
Femoral artery transection & rat & Heinius [82] \\
& pig & Hirst [83] \\
\hline Solid organ injury & & \\
Massive splenic injury & rat & Krausz [84] \\
& rat & Krausz [85] \\
& pig & Sondeen [86] \\
Standardized liver trauma & dog & Varicoda [87] \\
& rat & Matsuoka [88] \\
& pig & Todd [89] \\
& pig & Kiraly [90] \\
\hline Amputation of appendage & & \\
Tail amputation & rat & Kentner [91] \\
& rat & Capone [92] \\
& rat & Krausz [93] \\
\hline
\end{tabular}

In the last decade, more sophisticated uncontrolled hemorrhagic shock models evolved, especially with regard to studies on the efficiency of different fluid resuscitation strategies and other interventions such as hypothermia and hemostatic products [78-93] (tables 1, 4).

Recently, some authors have reported initial differences in the hemodynamic responses between controlled and uncontrolled hemorrhage. In cases of fixed-pressure and fixedvolume hemorrhage, there is a predictable relationship between blood volume and blood pressure; in the event of uncontrolled hemorrhage there is inequality in the extent of hypotension and the magnitude of blood loss. Based on this observation, certain other factors are suggested to influence blood pressure regulation in uncontrolled hemorrhagic shock. Sondeen et al. [94] hypothesized that the rate of blood loss may attenuate the baroreflex response in uncontrolled hemorrhage, perhaps by the Bezold-Jarisch reflex (depressor reflex), leading to a vagal nerve-mediated withdrawal of venous sympathetic tone and consequential reduction of cardiac output and mean arterial pressure. Other studies showed that the nociceptive stimulation of somatic afferent nerves or tissue injury (caused by induction of uncontrolled hemorrhage) can also modify the hemodynamic response to hemorrhage [95]. Nevertheless, further investigations are needed to understand this hemodynamic difference between controlled and uncontrolled hemorrhage. 


\section{Hemorrhagic Shock Models Based on Oxygen Debt}

The last century brought significant developments regarding the definition of shock. In 1941, Blalock [96] characterized shock as 'a peripheral circulatory failure, resulting from a discrepancy in the size of the vascular bed and the volume of the intravascular fluid'. Nowadays, the attention of researchers is focused on inadequate tissue perfusion and oxygenation. This is reflected in the present definition of shock by the American College of Surgeons [97]: 'Shock is an abnormality of the circulatory system that results in inadequate organ perfusion and tissue oxygenation.' Due to the critical decrease of tissue perfusion, disparity occurs between the oxygen consumption and oxygen delivery of cells, and oxygen debt develops [98]. Crowell and Smith [99] were the first to describe the relationship between oxygen debt and shock severity. This study led to the development of the fourth general category of hemorrhagic shock models, based on shock-induced oxygen debt [100]. Dunham et al. [101] were the first to create a dog model in which the primary endpoint was oxygen debt independent of blood pressure or hemorrhage volume. This and subsequent studies highlighted that oxygen debt and the metabolic consequences (lactic acidemia and base deficit) reflect the extent of tissue and organ damage better than the traditional variables such as bleeding volume and blood pressure.

\section{Confounding Variables}

Despite careful planning of experiments, complications may be caused by several variables; the most important ones are detailed below.

Gender is a determining factor in these experiments. Several clinical and experimental studies show some differences between males and females in terms of susceptibility to shock, trauma and sepsis. Diodato et al. [102] showed that females have a survival advantage over males in a 'two-hit' model of hemorrhagic shock (first hit) and subsequent sepsis (second hit). It was previously demonstrated that the cell-mediated immune response is depressed in males, while it is maintained or increased in females after hemorrhage. It is assumed that female sex hormones are responsible for maintaining immune function following hemorrhage [103].

Age is also an important factor in clinical and experimental models of hemorrhagic shock. Nickel et al. [104] showed that in mice, the immune response decreases with age following the presence of a harmful agent. Later, Matsutani et al. [105] demonstrated that hepatic damage after shock in combined multiple traumas and hemorrhage is dependent on age in mice.

Hemorrhagic animal models, in particular when combined with other types of tissue trauma, require anesthetic and analgesic drugs to eliminate pain. However, anesthesia usually depresses respiration, reduces metabolic demand [106], influences the central nervous system [107] and moderates cardiovascular compensatory mechanisms [108]. Furthermore, certain anesthetics change the immune function (production of cytokines and activity of natural killer cells) [109] and may facilitate bacterial translocation [110].

As a result, the use of conscious models is essential in order to estimate the cardiovascular, neuroendocrine and immune responses to hemorrhage correctly. Accordingly, many researchers seek to minimize the length of anesthesia. Le Page [111] was the first to study fixed-volume hemorrhagic shock in the absence of anesthesia; rats were temporarily anesthetized with ether and restrained in the supine position, then after awakening bleeding was induced by cutting the tail until circulatory failure occurred. As an alternative to this, Collins and Stechenberg [112] used femoral arterial catheters to induce shock. Sayeed and Baue [113] transformed the latter procedure into a fixed-pressure model; rats were anesthetized with ether and restrained in a sling, and both femoral arteries were cannulated. One of the arteries was used to check blood pressure, the other for blood withdrawal until the mean arterial pressure decreased to $40 \mathrm{~mm} \mathrm{Hg}$. This pressure was then maintained as best as possible by means of repeated hemorrhage or saline in fusion when required [113]. 
An essential issue is the use of heparin, especially in the case of fixed-pressure models. In his experiment, Wiggers [51] already observed that blood clots increased after bleeding; he therefore used heparin to prevent catheter clotting. This approach differs significantly from the clinical situation. In addition, preheparinization significantly ameliorates the microvasculatory status. The underlying mechanism is still not fully understood. It is assumed that heparin influences the serum levels of catecholamines and cytokines, blood viscosity, endothelial cell interactions and the coagulation cascade [114].

Trauma and surgery patients usually suffer from other tissue or organ injuries besides hemorrhagic shock. It is known that tissue damage can alter hemodynamic and inflammatory responses to acute blood loss. Cytokines released from injured tissue significantly alter organ dysfunction related to bleeding [115]. Thus, a clinically relevant model must take into account these conditions as well. In the following, hemorrhagic shock models combined with other injuries are detailed.

\section{Hemorrhagic Shock Combined with Traumatic Injury}

Trauma (caused by accidents, especially car crashes) is one of the leading causes of hypovolemic shock and death. Trauma patients suffer from soft tissue injuries and fractures as well as internal organ damage. Many models combined with hemorrhagic shock and other injuries were developed for the more accurate understanding of such life-threatening clinical conditions.

Mostly fixed-pressure hemorrhagic models are used to examine the aggravating effect of soft tissue injury on blood loss. In this instance, after the state of shock, tissue damage is usually caused by abdominal incision. Chaudry et al. [116] observed that mortality after laparotomy and hemorrhagic shock was significantly higher than after shock alone. The studies of Lu et al. [117] showed that ischemic damage of the small intestine was increased considerably after laparotomy.

Bone fractures, especially long bone fractures, may result in severe tissue injuries and significant blood loss. Most often, models combined with hemorrhagic shock and femur/tibia fracture are used for examination of this condition. Redl et al. [72] created hind limb fracture in a fixed-pressure hemorrhagic dog model. They were able to draw useful conclusions related to a trauma-induced increase in lung water content. Gill et al. [118] assessed systemic inflammation and subsequent organ damage caused by bilateral femur fracture connected to hypovolemic shock.

A number of models combined with internal organ injuries and hemorrhage were also developed. Significant abdominal bleeding and a subsequent state of shock are often caused by liver and spleen laceration. During such experiments, the rate of bleeding is not controlled, which complicates standardization of these operations. Krausz et al. [119] provoked circulatory failure by spleen injury in rats, while Brundage et al. [120] induced the same in pigs by grade $V$ liver injury (parenchymal damage involving more than $75 \%$ of liver mass accompanied by juxtahepatic venous injuries) to examine the changes in serum cytokine levels after trauma.

The clinically most relevant experimental settings are the multiple trauma models combined with hemorrhagic shock. However, during these experiments the animals suffer from excessive stress, causing their death in an early phase of the studies. Moreover, because of the complexity of the operations, repetition of measurements is complicated. Howes et al. [121] investigated the effect of recombinant factor VIIa in a polytraumatic (femur fracture, liver laceration and soft tissue crush injury) pig model. Alam et al. [122] examined the efficacy of treatment with valproic acid in pigs using a highly lethal polytrauma and hemorrhagic shock model [femur fracture, $60 \%$ hemorrhage (mean arterial pressure $25-30 \mathrm{~mm} \mathrm{Hg}$ ) and grade $V$ liver injury]. 


\section{Lower Limb Ischemia-Reperfusion Injury and Hemorrhagic Shock}

An extremity wound with macrovascular injury and bleeding quickly leads to a state of shock and, without intervention, to death. Recently, tourniquets have been used for hemorrhage control, especially in military trauma care. After an extended period of time, the use of a tourniquet can result in ischemia-reperfusion injury of the skeletal muscle once the tourniquet is released. Kauvar et al. [123] compared the effect of Ringer's lactate solution and Hextend in these conditions in rats. They used carotid arterial catheters to remove $67 \%$ of the total blood volume and to induce shock. At the time of development of shock, they placed a pneumatic digital tourniquet around a randomly selected hind limb on which they induced a 3-hour-long limb ischemia [123]. In a very similar model, Labruto et al. [124] examined the effect of lazaroid against ischemia-reperfusion injury. After the lazaroid pretreatment, they produced a 2-hour-long shock state, then performed fluid resuscitation with blood and Ringer's lactate solution. From the beginning of shock to the end of resuscitation, they used a tourniquet around one of the lower limbs. After removal of the tourniquet, the animals were observed for a further $3.5 \mathrm{~h}$ [124].

\section{Ruptured Abdominal Aortic Aneurysm and Hemorrhagic Shock}

Critical levels of blood loss may develop during the most serious complication of abdominal aortic aneurysm, the rupture of the aneurysm sac. Prehospital survival is only possible if the bleeding does not break into the peritoneum and is tamponed by the surrounding tissues. The principal therapy of the disease is surgical, but appropriate pre- and intraoperative fluid administration is just as crucial. The mortality rate of the disease is still around $40-50 \%$, so a great number of preclinical studies have been and are still currently being conducted [125].

The simulation of the clinical setting is usually achieved by abdominal aortic tear or aortotomy. Owens et al. [126] compared standard (to $100 \%$ of baseline) and limited (to $60 \%$ of baseline) prehospital resuscitation after abdominal aortic tear in pigs while examining the volume of intraperitoneal bleeding and hemoglobin loss. Later, numerous similar studies were conducted with a very low mortality rate in untreated control groups. Apparently, the resulting damage is incapable of causing life-threatening blood loss. Therefore, Kowalenko et al. [127] modified the procedure as follows: prior to creating an aortotomy, animals were exsanguinated from a femoral artery catheter to achieve a mean arterial pressure of $30 \mathrm{~mm} \mathrm{Hg}$. Animals were then bled with aortic tear until reaching an arterial pressure of $5 \mathrm{~mm} \mathrm{Hg}$ [127].

Harkin et al. [128] set up a rat model to examine ruptured abdominal aortic aneurysm, including the vascular occlusion used during the surgical procedure. In this event, a 'two-hit' lower limb ischemia-reperfusion injury and a subsequent systemic inflammatory response syndrome are assumed, caused by hemorrhagic shock and aortic clamping. Anesthetized rats underwent $1 \mathrm{~h}$ of hemorrhagic shock (mean arterial blood pressure $<50 \mathrm{~mm} \mathrm{Hg}$ ), followed by 45 min of supramesenteric aortic clamping, then $2 \mathrm{~h}$ of resuscitated (with shed blood and Ringer's lactate solution) reperfusion [128].

\section{Conclusions}

Animal experiments still have an essential role in the field of medical research. A major challenge for investigators is to generate a system which is simple, easily reproducible and standardized, at the same time being an accurate replica of the clinical circumstances of patients with life-threatening hemorrhage.

Due to their unique characteristics, it is difficult to decide which of the hemorrhagic shock models is the most suitable. Considering controllability and reproducibility, the pressureand volume-controlled models are preferred to uncontrolled hemorrhage models, since they 
are more appropriate for studies on the pathophysiology of shock and exploratory assessment of therapies. On the other hand, uncontrolled hemorrhage models, especially combined with other traumas, are more clinically relevant and more suitable for preclinical testing of various treatment strategies.

However, it is important to recognize the conflict between the aims of researchers and the clinical reality. In order to reduce confounding variables, research scientists usually use healthy animals of the same sex and age and reduce the reality to a specific part of the whole complex clinical situation (bleeding, hypothermia, hypotension, hypoxia, acidosis, coagulopathy and commonly accompanying tissue or organ injury). Furthermore, the fact that differences exist between human and animal physiology makes it significantly difficult to draw conclusions regarding clinical reality. Despite these considerations, carefully planned, complex preclinical trials are necessary for more accurate analysis of the conditions of hemorrhagic shock.

\section{Disclosure Statement}

The authors report no conflicts of interest.

\section{References}

1 Nunez TC, Cotton BA: Transfusion therapy in hemorrhagic shock. Curr Opin Crit Care 2009;15:536-541.

- 2 Hamar J, Kovach AG, Reivich M, Nyary I, Durity F: Effect of phenoxybenzamine on cerebral blood flow and metabolism in the baboon during hemorrhagic shock. Stroke 1979;10:401-407.

- 3 Kovach AG, Mitsanyi A, Monos E, Nyary I, Sulyok A: Control of organ blood flow following hemorrhage. Adv Exp Med Biol 1972;33:1-17.

- 4 Gutierrez G, Reines HD, Wulf-Gutierrez ME: Clinical review: hemorrhagic shock. Crit Care 2004;8:373-381.

- 5 Swanson KS, Mazur MJ, Vashisht K, Rund LA, Beever JE, Counter CM, Schook LB: Genomics and clinical medicine: rationale for creating and effectively evaluating animal models. Exp Biol Med 2004;229:866-875.

- 6 Majde JA: Animal models for hemorrhage and resuscitation research. J Trauma 2003;54:S100-S105.

- 7 Frink M, Andruszkow H, Zeckey C, Krettek C, Hildebrand F: Experimental trauma models: an update. J Biomed Biotechnol 2011;2011:797383.

- 8 Hauser C: Preclinical models of traumatic, hemorrhagic shock. Shock 2005;24(suppl 1):24-32.

- 9 Kemming G, Messick JB, Mueller W, Enders G, Meisner F, Muenzing S, Kisch-Wedel H, Schropp A, Wojtczyk C, Packert K, Messmer K, Thein E: Can we continue research in splenectomized dogs? Mycoplasma haemocanis: old problem - new insight. Eur Surg Res 2004;36:198-205.

10 Cheung AT, Duong PL, Driessen B, Chen PC, Jahr JS, Gunther RA: Systemic function, oxygenation and microvascular correlation during treatment of hemorrhagic shock with blood substitutes. Clin Hemorheol Microcirc 2006;34:325-334.

11 Carroll RG, Iams SG, Pryor WH Jr, Allison EJ Jr: Single hemorrhage: a clinically relevant canine model of hemorrhagic shock. Resuscitation 1988;16:119-126.

12 Hannon J: Hemorrhage and hemorrhagic-shock in swine - a review; in Swindle M (ed): Swine as Models in Biomedical Research. Ames, Iowa State University Press, 1992, pp 197-245.

13 Lomas-Niera J, Perl M, Chung C, Ayala A: Shock and hemorrhage: an overview of animal models. Shock 2005; 24 (suppl 1):33-39.

14 Mikkelsen T, Hillier L, Eichler E, Zody M, Jaffe D, Yang S, Enard W, Hellmann I, Lindblad-Toh K, Altheide T, Archidiacono N, Bork P, Butler J, Chang J, Cheng Z, Chinwalla A, deJong P, Delehaunty K, Fronick C, Fulton L, Gilad Y, Glusman G, Gnerre S, Graves T, Hayakawa T, Hayden K, Huang X, Ji H, Kent W, King M, Kulbokas E, Lee M, Liu G, Lopez-Otin C, Makova K, Man O, Mardis E, Mauceli E, Miner T, Nash W, Nelson J, Paabo S, Patterson N, Pohl C, Pollard K, Prufer K, Puente X, Reich D, Rocchi M, Rosenbloom K, Ruvolo M, Richter D, Schaffner S, Smit A, Smith S, Suyama M, Taylor J, Torrents D, Tuzun E, Varki A, Velasco G, Ventura M, Wallis J, Wendl M, Wilson R, Lander E, Waterston R; Chimpanzee Sequencing and Analysis Consortium: Initial sequence of the chimpanzee genome and comparison with the human genome. Nature 2005;437:69-87.

15 Redl H, Bahrami S: Large animal models: baboons for trauma, shock, and sepsis studies. Shock 2005;24(suppl 1):88-93.

16 Schlag G, Redl H, Till G, Davies J, Martin U, Dumont L: Anti-L-selectin antibody treatment of hemorrhagic-traumatic shock in baboons. Crit Care Med 1999;27:1900-1907.

17 Deitch E: Animal models of sepsis and shock: a review and lessons learned. Reply. Shock 1998;10:442-445.

18 Gainer J, Lipa M, Ficenec M: Hemorrhagic-shock in rats. Lab Anim Sci 1995;45:169-172. 
19 Frankel DA, Acosta JA, Anjaria DJ, Porcides RD, Wolf PL, Coimbra R, Hoyt DB: Physiologic response to hemorrhagic shock depends on rate and means of hemorrhage. J Surg Res 2007;143:276-280.

20 Diehl KH, Hull R, Morton D, Pfister R, Rabemampianina Y, Smith D, Vidal JM, van de Vorstenbosch C: A good practice guide to the administration of substances and removal of blood, including routes and volumes. J Appl Toxicol 2001;21:15-23.

21 Pellicane JV, Gore DC, DeMaria EJ: Decreased lactate in endotoxin-resistant mice undergoing hemorrhage is independent of tumor necrosis factor availability. J Surg Res 1994;56:361-366.

22 Rajnik M, Salkowski CA, Thomas KE, Li YY, Rollwagen FM, Vogel SN: Induction of early inflammatory gene expression in a murine model of nonresuscitated, fixed-volume hemorrhage. Shock 2002;17:322-328.

23 Oberbeck R, Nickel E, von Griensven M, Tschernig T, Wittwer T, Schmitz D, Pape HC: The effect of dehydroepiandrosterone on hemorrhage-induced suppression of cellular immune function. Intensive Care Med 2002;28: 963-968.

24 Hewitt PM, Armstrong N, Bowrey P, Cherian M, Morris DL: Cimetidine prevents suppression of delayed hypersensitivity in an animal model of haemorrhagic shock. Injury 2002;33:673-678.

25 Mackrell PJ, Daly JM, Mestre JR, Stapleton PP, Howe LR, Subbaramaiah K, Dannenberg AJ: Elevated expression of cyclooxygenase- 2 contributes to immune dysfunction in a murine model of trauma. Surgery 2001;130: 826-833.

26 Dennis AM, Haselkorn ML, Vagni VA, Garman RH, Janesko-Feldman K, Bayir H, Clark RS, Jenkins LW, Dixon CE, Kochanek PM: Hemorrhagic shock after experimental traumatic brain injury in mice: effect on neuronal death. J Neurotrauma 2009;26:889-899.

-27 Zakaria el Rasheid, Garrison RN, Kawabe T, Harris PD: Direct peritoneal resuscitation from hemorrhagic shock: effect of time delay in therapy initiation. J Trauma 2005;58:499-506, discussion 506-508.

-28 Fukudome EY, Kochanek AR, Li Y, Smith EJ, Liu B, Kheirbek T, Lu J, Kim K, Hamwi K, Velmahos GC, Alam HB: Pharmacologic resuscitation promotes survival and attenuates hemorrhage-induced activation of extracellular signal-regulated kinase 1/2. J Surg Res 2010;163:118-126.

29 Guarini S, Bazzani C, Ricigliano GM, Bini A, Tomasi A, Bertolini A: Influence of ACTH-(1-24) on free radical levels in the blood of haemorrhage-shocked rats: direct ex vivo detection by electron spin resonance spectrometry. Br J Pharmacol 1996;119:29-34.

-30 Johnson RA, Durante W, Craig T, Peyton KJ, Myers JG, Stewart RM, Johnson FK: Vascular arginase contributes to arteriolar endothelial dysfunction in a rat model of hemorrhagic shock. J Trauma 2010;69:384-391.

-31 Kretschmar K, Rosenthal V: Cytoskeletal alterations in endothelial cells of mesenteric microcirculatory bed in experimental traumatic haemorrhagic shock. Acta Histochem Suppl 1991;41:265-270.

-32 Troy BP, Heslop DJ, Bandler R, Keay KA: Haemodynamic response to haemorrhage: distinct contributions of midbrain and forebrain structures. Auton Neurosci 2003;108:1-11.

-33 Santibanez-Gallerani AS, Barber AE, Williams SJ, Zhao Y, Shires GT: Hepatic integrity dependent on matrix metalloproteinase inhibition, not tumor necrosis factor alpha or different bleeding rates. J Surg Res 2000;90: 156-160.

34 Crippen D, Safar P, Snyder C, Porter L: Dying pattern in volume-controlled hemorrhagic shock in awake rats. Resuscitation 1991;21:259-270.

-35 Hall C, Malkevich N, Handrigan M, Vandermolen C, Aranaud F, Hong J, Dong F, Rice J, Philbin N, Ahlers S, McCarron R, Freilich D, McGwin G, Flournoy WS, Pearce LB: Innate immune responses in swine resuscitated from severe traumatic hemorrhagic shock with hemoglobin-based oxygen carrier-201. Artif Cells Blood Substit Immobil Biotechnol 2007;35:259-274.

-36 Herff H, Paal P, von Goedecke A, Lindner KH, Severing AC, Wenzel V: Influence of ventilation strategies on survival in severe controlled hemorrhagic shock. Crit Care Med 2008;36:2613-2620.

- 37 Xanthos TT, Balkamou XA, Stroumpoulis KI, Pantazopoulos IN, Rokas GI, Agrogiannis GD, Troupis GT, Demestiha TD, Skandalakis PN: A model of hemorrhagic shock and acute lung injury in landrace-large white swine. Comp Med 2011;61:158-162.

-38 Noritomi DT, Pereira AJ, Bugano DD, Rehder PS, Silva E: Impact of Plasma-Lyte pH 7.4 on acid-base status and hemodynamics in a model of controlled hemorrhagic shock. Clinics (Sao Paulo) 2011;66:1969-1974.

39 van Iterson M, Bezemer R, Heger M, Siegemund M, Ince C: Microcirculation follows macrocirculation in heart and gut in the acute phase of hemorrhagic shock and isovolemic autologous whole blood resuscitation in pigs. Transfusion 2012;52:1552-1559.

40 Arnaud F, Scultetus AH, Haque A, Saha B, Kim B, Auker C, Moon-Massat P, McCarron R, Freilich D: Sodium nitroprusside ameliorates systemic but not pulmonary HBOC-201-induced vasoconstriction: an exploratory study in a swine controlled haemorrhage model. Resuscitation 2012;83:1038-1045.

41 Crookes B, Cohn S, Bonet H, Burton E, Nelson J, Majetschak M, Varon A, Linden J, Proctor K: Building a better fluid for emergency resuscitation of traumatic brain injury. J Trauma 2004;57:547-554.

42 Gibson J, Maxwell R, Schweitzer J, Fabian T, Proctor K: Resuscitation from severe hemorrhagic shock after traumatic brain injury using saline, shed blood, or a blood substitute. Shock 2002;17:234-244.

43 Jacobsen J, Sofelt S, Sheikh S, Warberg J, Secher NH: Cardiovascular and endocrine responses to haemorrhage in the pig. Acta Physiol Scand 1990;138:167-173.

-44 Frey L, Kesel K, Pruckner S, Pacheco A, Welte M, Messmer K: Is sodium acetate dextran superior to sodium chloride dextran for small volume resuscitation from traumatic hemorrhagic shock? Anesth Analg 1994;79: 517-524. 
45 Li KC, Pelc LR, Puvvala S, Wright GA: Mesenteric ischemia due to hemorrhagic shock: MR imaging diagnosis and monitoring in a canine model. Radiology 1998;206:219-225.

-46 Nascimento P Jr, de Paiva Filho 0, de Carvalho LR, Braz JR: Early hemodynamic and renal effects of hemorrhagic shock resuscitation with lactated Ringer's solution, hydroxyethyl starch, and hypertonic saline with or without 6\% dextran-70. J Surg Res 2006;136:98-105.

47 Braz JR, do Nascimento P Jr, Paiva Filho O, Braz LG, Vane LA, Vianna PT, Rodrigues GR Jr: The early systemic and gastrointestinal oxygenation effects of hemorrhagic shock resuscitation with hypertonic saline and hypertonic saline 6\% dextran-70: a comparative study in dogs. Anesth Analg 2004;99:536-546, table of contents.

-48 Yamamoto M, Horinouchi H, Kobayashi K, Seishi Y, Sato N, Itoh M, Sakai H: Fluid resuscitation of hemorrhagic shock with hemoglobin vesicles in beagle dogs: pilot study. Artif Cells Blood Substit Immobil Biotechnol 2012; 40:179-195.

49 Glick YA, Wilson LD, Aiello J: Hematocrit and metabolic changes caused by varied resuscitation strategies in a canine model of hemorrhagic shock. Am J Emerg Med 2002;20:303-309.

50 Penfield W: The treatment of severe and progressive hemorrhage by intravenous injections. Am J Physiol 1919;48:121-132.

51 Wiggers CJ: The present status of the shock problem. Physiol Rev 1942;22:74-123.

52 Ayala A, Wang P, Chaudry I: Shock models: hemorrhage; in Souba W, Wilmore D (eds): Surgical Research. San Diego, Academic Press, 2001, pp 357-366.

53 Kawasaki T, Fujimi S, Lederer JA, Hubbard WJ, Choudhry MA, Schwacha MG, Bland KI, Chaudry IH: Traumahemorrhage induces depressed splenic dendritic cell functions in mice. J Immunol 2006;177:4514-4520.

54 Murao Y, Isayama K, Saito F, Hirakawa A, Nakatani T: Effect of hypertonic saline resuscitation on CD4+CD25+ regulatory T cells and gammadelta $\mathrm{T}$ cells after hemorrhagic shock and resuscitation in relation to apoptosis and iNOS. J Trauma 2009;67:975-982.

55 Hsieh CH, Nickel EA, Hsu JT, Schwacha MG, Bland KI, Chaudry IH: Trauma-hemorrhage and hypoxia differentially influence kupffer cell phagocytic capacity: role of hypoxia-inducible-factor-1alpha and phosphoinositide 3-kinase/akt activation. Ann Surg 2009;250:995-1001.

56 Samy T, Ayala A, Catania R, Chaudry I: Trauma-hemorrhage activates signal transduction pathways in mouse splenic T cells. Shock 1998;9:443-450.

57 Schneider C, Nickel E, Samy T, Schwacha M, Cioffi W, Bland K, Chaudry I: The aromatase inhibitor, 4-hydroxyandrostenedione, restores immune responses following trauma-hemorrhage in males and decreases mortality from subsequent sepsis. Shock 2000;14:347-353.

-58 Cai C, Gill R, Eum HA, Cao Z, Loughran PA, Darwiche S, Edmonds RD, Menzel CL, Billiar TR: Complement factor 3 deficiency attenuates hemorrhagic shock-related hepatic injury and systemic inflammatory response syndrome. Am J Physiol Regul Integr Comp Physiol 2010;299:R1175-R1182.

59 Cai B, Dong W, Sharpe S, Deitch EA, Ulloa L: Survival and inflammatory responses in experimental models of hemorrhage. J Surg Res 2011;169:257-266.

60 Gonzalez RJ, Moore EE, Ciesla DJ, Nieto JR, Johnson JL, Silliman CC: Post-hemorrhagic shock mesenteric lymph activates human pulmonary microvascular endothelium for in vitro neutrophil-mediated injury: the role of intercellular adhesion molecule-1. J Trauma 2003;54:219-223.

-61 Hoppen RA, Corso CO, Grezzana TJ, Severino A, Dal-Pizzol F, Ritter C: Hypertonic saline and hemorrhagic shock: hepatocellular function and integrity after six hours of treatment. Acta Cir Bras 2005;20:414-417.

62 Rupani B, Caputo FJ, Watkins AC, Vega D, Magnotti LJ, Lu Q, Xu da Z, Deitch EA: Relationship between disruption of the unstirred mucus layer and intestinal restitution in loss of gut barrier function after trauma hemorrhagic shock. Surgery 2007;141:481-489.

-63 Yang R, Harada T, Mollen KP, Prince JM, Levy RM, Englert JA, Gallowitsch-Puerta M, Yang L, Yang H, Tracey KJ, Harbrecht BG, Billiar TR, Fink MP: Anti-HMGB1 neutralizing antibody ameliorates gut barrier dysfunction and improves survival after hemorrhagic shock. Mol Med 2006;12:105-114.

64 Zingarelli B, Ischiropoulos H, Salzman AL, Szabo C: Amelioration by mercaptoethylguanidine of the vascular and energetic failure in haemorrhagic shock in the anesthetised rat. Eur J Pharmacol 1997;338:55-65.

65 Chiara O, Pelosi P, Brazzi L, Bottino N, Taccone P, Cimbanassi S, Segala M, Gattinoni L, Scalea T: Resuscitation from hemorrhagic shock: experimental model comparing normal saline, dextran, and hypertonic saline solutions. Crit Care Med 2003;31:1915-1922.

66 George ME, Mulier KE, Beilman GJ: Hypothermia is associated with improved outcomes in a porcine model of hemorrhagic shock. J Trauma 2010;68:662-668.

67 Soller BR, Khan T, Favreau J, Hsi C, Puyana JC, Heard SO: Investigation of muscle pH as an indicator of liver $\mathrm{pH}$ and injury from hemorrhagic shock. J Surg Res 2003;114:195-201.

68 Szebeni J, Baranyi L, Savay S, Gotze O, Alving CR, Bunger R, Mongan PD: Complement activation during hemorrhagic shock and resuscitation in swine. Shock 2003;20:347-355.

-69 Oda J, Ivatury RR, Blocher CR, Malhotra AJ, Sugerman HJ: Amplified cytokine response and lung injury by sequential hemorrhagic shock and abdominal compartment syndrome in a laboratory model of ischemiareperfusion. J Trauma 2002;52:625-631, discussion 632.

-70 York GB, Eggers JS, Smith DL, Jenkins DH, McNeil JD, Mueller D, Josephs JD, Kerby JD: Low-volume resuscitation with a polymerized bovine hemoglobin-based oxygen-carrying solution (HBOC-201) provides adequate tissue oxygenation for survival in a porcine model of controlled hemorrhage. J Trauma 2003;55:873-885. 
71 Cooper ES, Bateman SW, Muir WW: Evaluation of hyperviscous fluid resuscitation in a canine model of hemorrhagic shock: a randomized, controlled study. J Trauma 2009;66:1365-1373.

72 Redl H, Krosl P, Schlag G, Hammerschmidt D: Permeability studies in a hypovolemic traumatic shock model - comparison of Ringer's lactate and albumin as volume replacement fluids. Resuscitation 1989;17:77-90.

73 Garcia-Martinez D, Portilla-de Buen E, Leal C, Santillan P, Muniz J: The immediate response to severe shock in a canine model with a combination of hypertonic-hyperoncotic solution with naloxone. Shock 2006;26:379385.

74 Huang Y, Zeng Q, Luo A: The change of arteriovenous carbon dioxide and $\mathrm{pH}$ gradients during severe hemorrhagic shock and resuscitation. Chin Med Sci J 1998;13:53-55.

75 Poole GV Jr, Prough DS, Johnson JC, Stullken EH, Stump DA, Howard G: Effects of resuscitation from hemorrhagic shock on cerebral hemodynamics in the presence of an intracranial mass. J Trauma 1987;27:18-23.

76 Bedirli A, Sozuer EM, Muhtaroglu S, Alper M: The role of oxygen free radicals and nitric oxide in organ injury following hemorrhagic shock and reinfusion. Int J Surg Investig 2000;2:275-284.

77 Cannon W, Frasen J, Cowel E: The preventive treatment of wound shock. JAMA 1918;70:618-621.

78 Burris D, Rhee P, Kaufmann C, Pikoulis E, Austin B, Eror A, DeBraux S, Guzzi L, Leppaniemi A: Controlled resuscitation for uncontrolled hemorrhagic shock. J Trauma 1999;46:216-223.

79 Bickell WH, Bruttig SP, Millnamow GA, O’Benar J, Wade CE: The detrimental effects of intravenous crystalloid after aortotomy in swine. Surgery 1991;110:529-536.

80 Alam HB, Punzalan CM, Koustova E, Bowyer MW, Rhee P: Hypertonic saline: intraosseous infusion causes myonecrosis in a dehydrated swine model of uncontrolled hemorrhagic shock. J Trauma 2002;52:18-25.

81 Bruscagin V, de Figueiredo LF, Rasslan S, Varicoda EY, Rocha e Silva M: Fluid resuscitation improves hemodynamics without increased bleeding in a model of uncontrolled hemorrhage induced by an iliac artery tear in dogs. J Trauma 2002;52:1147-1152.

82 Heinius G, Hahn RG, Sonden A: Hypothermia increases rebleeding during uncontrolled hemorrhage in the rat. Shock 2011;36:60-66.

83 Hirst H, Brinkman J, Beasley A, Crocker R, O’Sullivan J: The effects of blood pressure on rebleeding when using ExcelArrest ${ }^{\mathrm{TM}}$ in a porcine model of lethal femoral injury. J Emerg Trauma Shock 2011;4:207-211.

84 Krausz MM, Hirsh M: Bolus versus continuous fluid resuscitation and splenectomy for treatment of uncontrolled hemorrhagic shock after massive splenic injury. J Trauma 2003;55:62-68.

85 Krausz M, Bashenko Y, Hirsh M: Crystalloid or colloid resuscitation of uncontrolled hemorrhagic shock after moderate splenic injury. Shock 2000;13:230-235.

86 Sondeen JL, Prince MD, Kheirabadi BS, Wade CE, Polykratis IA, de Guzman R, Dubick MA: Initial resuscitation with plasma and other blood components reduced bleeding compared to hetastarch in anesthetized swine with uncontrolled splenic hemorrhage. Transfusion 2011;51:779-792.

87 Varicoda EY, Poli de Figueiredo LF, Cruz RJ Jr, Silva LE, Rocha e Silva M: Blood loss after fluid resuscitation with isotonic or hypertonic saline for the initial treatment of uncontrolled hemorrhage induced by spleen rupture. J Trauma 2003;55:112-117.

88 Matsuoka T, Hildreth J, Wisner DH: Liver injury as a model of uncontrolled hemorrhagic shock: resuscitation with different hypertonic regimens. J Trauma 1995;39:674-680.

89 Todd SR, Malinoski D, Muller PJ, Schreiber MA: Lactated Ringer's is superior to normal saline in the resuscitation of uncontrolled hemorrhagic shock. J Trauma 2007;62:636-639.

90 Kiraly L, Differding J, Enomoto T, Sawai R, Muller P, Diggs B, Tieu B, Englehart M, Underwood S, Wiesberg T, Schreiber M: Resuscitation with normal saline (NS) vs. lactated ringers (LR) modulates hypercoagulability and leads to increased blood loss in an uncontrolled hemorrhagic shock swine model. J Trauma 2006;61:57-64.

91 Kentner R, Safar P, Behringer W, Wu X, Henchir J, Ma L, Hsia CJ, Tisherman SA: Small volume resuscitation with tempol is detrimental during uncontrolled hemorrhagic shock in rats. Resuscitation 2007;72:295-305.

92 Capone AC, Safar P, Stezoski W, Tisherman S, Peitzman AB: Improved outcome with fluid restriction in treatment of uncontrolled hemorrhagic shock. J Am Coll Surg 1995;180:49-56.

93 Krausz MM, Horn Y, Gross D: The combined effect of small volume hypertonic saline and normal saline solutions in uncontrolled hemorrhagic shock. Surg Gynecol Obstet 1992;174:363-368.

94 Sondeen J, Dubick M, Holcomb J, Wade C: Uncontrolled hemorrhage differs from volume- or pressure-matched controlled hemorrhage in swine. Shock 2007;28:426-433.

95 Rady MY, Kirkman E, Cranley J, Little RA: Nociceptive somatic nerve stimulation and skeletal muscle injury modify systemic hemodynamics and oxygen transport and utilization after resuscitation from hemorrhage. Crit Care Med 1996;24:623-630.

96 Blalock A: Principles of surgical care, shock and other problems. JAMA 1941;116:548-548.

97 American College of Surgeons: Shock; in: Advanced Trauma Life Support Manual. Chicago, American College of Surgeons, 1997, pp 87-108.

98 Rixen D, Neugebauer EAM: Changing paradigms in animal models of traumatic/hemorrhagic shock. Eur J Trauma 2004;30:279-288.

99 Crowell JW, Smith EE: Oxygen deficit and irreversible hemorrhagic shock. Am J Physiol 1964;206:313-316.

100 Rixen D, Siegel JH: Bench-to-bedside review: oxygen debt and its metabolic correlates as quantifiers of the severity of hemorrhagic and post-traumatic shock. Crit Care 2005;9:441-453. 
101 Dunham CM, Siegel JH, Weireter L, Fabian M, Goodarzi S, Guadalupi P, Gettings L, Linberg SE, Vary TC: Oxygen debt and metabolic acidemia as quantitative predictors of mortality and the severity of the ischemic insult in hemorrhagic shock. Crit Care Med 1991;19:231-243.

102 Diodato MD, Knoferl MW, Schwacha MG, Bland KI, Chaudry IH: Gender differences in the inflammatory response and survival following haemorrhage and subsequent sepsis. Cytokine 2001;14:162-169.

103 Angele M, Schwacha M, Ayala A, Chaudry I: Effect of gender and sex hormones on immune responses following shock. Shock 2000;14:81-90.

104 Nickel E, Schwacha M, Schneider C, Bland K, Chaudry I: Trauma-haemorrhage-induced alterations in thymic prolactin receptor expression: implications in immune dysfunction. Cytokine 2002;18:127-132.

105 Matsutani T, Kang S, Miyashita M, Sasajima K, Choudhry M, Bland K, Chaudry I: Liver cytokine production and ICAM-1 expression following bone fracture, tissue trauma, and hemorrhage in middle-aged mice. Am J Physiol Gastrointest Liver Physiol 2007;292:268-274.

106 Brunner E, Cheng S, Berman M: Effects of anesthesia on intermediary metabolism. Annu Rev Med 1975;26: 391-401.

107 Hauser G, Dayao E, Zukowskagrojec Z: Effect of pentobarbital anesthesia on the pressor reponse to agonists in vivo in normal and endotoxemic rats. Res Commun Mol Pathol Pharmacol 1995;90:289-300.

108 Stenseth R, Berg E, Bjella L, Christensen O, Levang O, Gisvold S: The influence of thoracic epidural analgesia alone and in combination with general anesthesia on cardiovascular function and myocordial metabolism in patients receiving beta-adrenergic blockers. Anesth Analg 1993;77:463-468.

109 Kelbel I, Weiss M: Anaesthetics and immune function. Curr Opin Anaesthesiol 2001;14:685-691.

110 Hilburger M, Adler M, Truant A, Meissler J, Satishchandran V, Rogers T, Eisenstein T: Morphine induces sepsis in mice. J Infect Dis 1997;176:183-188.

111 Le Page GA: The effects of hemorrhage on tissue metabolites. Am J Physiol 1946;147:446-453.

112 Collins JA, Stechenberg L: The effects of the concentration and function of hemoglobin on the survival of rats after hemorrhage. Surgery 1979;85:412-418.

113 Sayeed MM, Baue AE: Mitochondrial metabolism of succinate, beta-hydroxybutyrate, and alpha-ketoglutarate in hemorrhagic shock. Am J Physiol 1971;220:1275-1281.

114 Rana M, Singh G, Wang P, Ayala A, Zhou M, Chaudry I: Protective effects of preheparinization on the microvasculature during and after hemmorhagic shock. J Trauma 1992;32:420-426.

115 Mackway-Jones K, Foex BA, Kirkman E, Little RA: Modification of the cardiovascular response to hemorrhage by somatic afferent nerve stimulation with special reference to gut and skeletal muscle blood flow. J Trauma 1999;47:481-485.

116 Chaudry I, Wang P, Singh G, Hauptman J, Ayala A: Rat and mouse models of hypovolemic-traumatic shock.; in Schlag G, Redl H (eds): Pathophysiology of Shock, Sepsis, and Organ Failure. Berlin, Springer, 1993, pp 371-383.

117 Lu Q, Xu D, Sharpe S, Doucet D, Pisarenko V, Lee M, Deitch E: The anatomic sites of disruption of the mucus layer directly correlate with areas of trauma/hemorrhagic shock-induced gut injury. J Trauma 2011;70:630635.

118 Gill R, Ruan X, Menzel C, Namkoong S, Loughran P, Hackam D, Billiar T: Systemic inflammation and liver injury following hemorrhagic shock and peripheral tissue trauma involve functional TLR9 signaling on bone marrowderived cells and parenchymal cells. Shock 2011;35:164-170.

119 Krausz M, Bashenko Y, Hirsh M: Improved survival in uncontrolled hemorrhagic shock induced by massive splenic injury in the proestrus phase of the reproductive cycle in the female rat. Shock 2003;20:444-448.

120 Brundage S, Schreiber M, Holcomb J, Zautke N, Mastrangelo M, Xq X, Macaitis J, Tweardy D: Amplification of the proinflammatory transcription factor cascade increases with severity of uncontrolled hemorrhage in swine. J Surg Res 2003;113:74-80.

121 Howes D, Stratford A, Stirling M, Ferri C, Bardell T: Administration of recombinant factor VIIa decreases blood loss after blunt trauma in noncoagulopathic pigs. J Trauma 2007;62:311-314.

122 Alam HB, Shuja F, Butt MU, Duggan M, Li Y, Zacharias N, Fukudome EY, Liu B, Demoya M, Velmahos GC: Surviving blood loss without blood transfusion in a swine poly-trauma model. Surgery 2009;146:325-333.

123 Kauvar D, Baer D, Dubick M, Walters T: Effect of fluid resuscitation on acute skeletal muscle ischemia-reperfusion injury after hemorrhagic shock in rats. J Am Coll Surg 2006;202:888-896.

124 Labruto F, Song X, Valen G, Vaage J: Lazaroid U-83836E improves tolerance to hemorrhagic shock and limb ischemia and reperfusion in rats and increases cardiac heat shock protein 72. Acad Emerg Med 2006;13:7-12.

125 Verhoeven E, Prins T, van den Dungen J, Tielliu I, Hulsebos R, van Schilfgaarde R: Endovascular repair of acute AAAs under local anesthesia with bifurcated endografts: a feasibility study. J Endovasc Ther 2002;9:729-735.

126 Owens TM, Watson WC, Prough DS, Uchida T, Kramer GC: Limiting initial resuscitation of uncontrolled hemorrhage reduces internal bleeding and subsequent volume requirements. J Trauma 1995;39:200-207, discussion 208-209.

127 Kowalenko T, Stern S, Dronen S, Xu W: Improved outcome with hypotensive resuscitation of uncontrolled hemorrhagic shock in a swine model. J Trauma 1992;33:349-353.

128 Harkin DW, Romaschin A, Taylor SM, Rubin BB, Lindsay TF: Complement C5a receptor antagonist attenuates multiple organ injury in a model of ruptured abdominal aortic aneurysm. J Vasc Surg 2004;39:196-206. 